OPEN ACCESS

Edited by:

Subramaniam Ramanathan, Nanyang Technological University,

Singapore

Reviewed by:

Kathryn Holmes,

Western Sydney University, Australia

Belinda Aeschlimann,

Swiss Federal Institute for Vocational

Education and Training, Switzerland

${ }^{*}$ Correspondence:

Robbert Smit

robbert.smit@phsg.ch

Specialty section:

This article was submitted to

STEM Education,

a section of the journal

Frontiers in Education

Received: 21 June 2019

Accepted: 26 March 2020

Published: 17 April 2020

Citation:

Smit R, Robin N and De Toffol C

(2020) Explaining Secondary

Students' Career Intentions for Technology and Engineering Jobs

Using an Expectancy-Value Model.

Front. Educ. 5:39.

doi: 10.3389/feduc.2020.00039

\section{Explaining Secondary Students' Career Intentions for Technology and Engineering Jobs Using an Expectancy-Value Model}

\author{
Robbert Smit*, Nicolas Robin and Christina De Toffol \\ St. Gallen University of Teacher Education, St. Gallen, Switzerland
}

This research presents an empirical model based on expectancy-value theory to explain students' attitudes toward science-based technology. The question is how students' attitudes are connected with their aspirations for a career in the technology and engineering fields. There is a high demand for technology professionals, but students' interest in such careers is low. The context of this study is a cooperation project involving local industry and Swiss secondary schools that aims to foster students' interest in science-based technology. We conducted a mix-methods study with a sample of 337 students in secondary school (grades 7-9) and 12 science teachers. Based on the questionnaire data, we created a structural equation model to analyze the relationships between students' expectancy-value attitudes and career interests. Context variables, such as gender, parents' professions, and having a workshop at home complement the model. With the help of the data collected in the teacher interviews, the results were validated and elaborated. The findings indicate students' attitudes and interest in science-based technology were rather low in general, and as expected, they were significantly lower for girls. Our 2-factor empirical model showed a stronger focus on application than on theory. Self-concept and values were predictors of career interests, but not of interest in applied science. Context variables also played a significant role. Triangulation of the data helped validate the measured constructs. In conclusion, our results indicate that school science lessons might not offer sufficient experiences in applied science to secondary school students. Interest in a career in the technology and engineering fields can be triggered by integrating more engineering experiences in the science classroom.

Keywords: career interest, student attitudes, science-based technology, secondary students, expectancy-value model

\section{INTRODUCTION}

Multiple research studies have reported a growing decline in students' interest in science, technology, engineering, and mathematics (STEM) subjects (Organisation for Economic Cooperation and Development [OECD], 2006b; Xie and Achen, 2009; Becker, 2010; Ngss Lead States, 2013). Students from all German-speaking countries scored below the Organisation for Economic 
Co-operation and Development (OECD) average on the 2006 Programme for International Student Assessment (PISA), which is related to students' general value of science and technology and to the present study's sample. More than $50 \%$ of the students answered that science and technology is not relevant to them. The 2015 PISA (Organisation for Economic Co-operation and Development [OECD], 2016) showed slightly better results, especially for Austria, but this increase was mainly due to students' growing interest in working as health professionals. Therefore, it remains important to raise students' interest in STEM subjects at school and STEM-related jobs in the technology and engineering fields.

Careers in the technology and engineering fields are unpopular among students leaving compulsory school (Becker, 2010; Dutrévis et al., 2017; Bryson et al., 2018). This is especially true for girls, who are often less interested in technology and underrepresented in the engineering professions (Riegle-Crumb et al., 2011; Robnett and Leaper, 2013; Güdel, 2014). Reasons for lack of interest in STEM have been explored previously (Nugent et al., 2015); however, a detailed empirical model predicting career interest in technology and engineering based on attitudes has not been tested. This focus is important because sciencebased technology has unique characteristics. "Science-based" has been added as a descriptor to distinguish this type of technology from the technology related to the use of computers in schools. Of particular significance is its active feature, compared to typical school-based science. The idea of practice is the central component of technological activity, and hence, the importance of technological practice (Jones, 2012).

Our research is embedded within a Swiss-Austrian project that aims to develop positive student attitudes toward technology, both in their classrooms and in their prospective careers by visiting STEM-related industries. Most of the students will continue their education by taking up apprenticeships. According to Archer et al. (2010), student identity is responsible for career choices in secondary school (grades 7-9), and this identity, which is related to interest in science, is largely formed between the ages of 10 and 14 years. This result has been confirmed by Maltese and Tai (2010) who reported that most of the scientists and graduate students who were interviewed for their study indicated that their initial interest in science occurred prior to entering middle school. Therefore, it is sensible to create projects to help students in that age group determine what career possibilities the technology and engineering fields have to offer. In many countries, technology is not yet a prominent feature of science education. The United States National Science Education standards integrated technology and engineering as early as 1996, but despite these early efforts, technology education has not received the same level of attention in the science curricula, assessments or the education of new science teachers as the traditional science disciplines (Ngss Lead States, 2013).

Targeted social and psychological interventions that focus on specific elements of student motivation have been used with success in different educational situations (Yeager and Walton, 2011). Out-of-school experiences can be a promising way to overcome possible shortcomings in the curriculum. Schoolindustry partnerships offer authentic learning opportunities and they can support the development of interest in a technology career.

In the first stage of our research, we were interested in the students' attitudes toward science-based technology in general, and how these attitudes interact in relation to the prediction of interest in a career in the technology and engineering fields. We applied an expectancy-value model adapted for science-based technology as a comprehensive framework for our study. A literature overview is presented in the following section and ends with the study's research questions. In the next (see section "Methods") section, a procedural diagram is presented, which serves as the organizational scheme for the methods, results, and interpretations reported in this article. The study ends with a summary, and a limitations and conclusion section with implications for research and practice.

\section{LITERATURE REVIEW}

\section{Technology Education}

The general public and many teachers perceive technology as applied science (Jones et al., 2013); however, this view is somewhat incomplete (Jones, 2012). In school, teachers and students should develop an understanding of technology and science as two areas that can interact but are also distinct in nature. This means that technology is often an applied science. Sometimes, however, there is no interaction when products are created without the proper understanding of their scientific background (De Vries, 2001). For instance, secondary school students could learn to assemble and use a 3-D printer in class without having knowledge of the molecular structure of thermoplastic. A recent study by Buckley et al. (2018) with Irish post-primary students (approximately 18 years old) showed that science and technology students acquired different types of knowledge and skills. The skills in technology education generally refer to procedural knowledge, much of this being tacit knowledge, whereas skills in the science subjects appear to represent methods for acquiring more propositional knowledge. Another ambiguity is that technology education is often confounded with the use of computers in schools. For clarification, in this study the term science-based technology from the PISA framework will be used occasionally (Fensham, 1988; Organisation for Economic Co-operation and Development [OECD], 2006a).

What topics should students encounter in science-based technology lessons? Bybee (2000) defines technology as a subject that provides students with opportunities to learn about the processes of design, fundamental concepts of technology and engineering, and the limits and possibilities of technology in society. Similar to Bybee (2000), Jones (2012) describes technology as anything that allows people to expand their possibilities and intervene in the world through the development of products, systems, and environments. This vision of technological education includes the discussion of social aspects, values, and ethics in the science classroom, and such themes are also more appealing to women (Su and Rounds, 2015). 
The United States Next Generation Science Standards (NGSS) for technology and engineering have become prominent. Here, the term "engineering" is used in a very broad sense to mean any engagement in the systematic practice of design to achieve solutions to particular human problems. Thus, in addition to science practices engineering practices are described in the NGSS for each disciplinary core concept. The appendices states that technology and engineering offer opportunities for students to deepen their understanding of science by applying their developing scientific knowledge to the solution of practical problems (Ngss Lead States, 2013).

In Swiss secondary schools, the subject of technology has not historically been a prominent component of the curriculum. The new Swiss "Curriculum 21" includes technology as part of science, with respect to being able to talk about the relevance and sustainability of technological inventions, such as genetic engineering, electric engines, and communication technologies. Students should also possess competencies to use and understand everyday tools (e.g., hair dryers, loudspeakers, and LED), and test and optimize technical devices. The practical implementation of the new Swiss curriculum is ongoing. Hence, it is reasonable to assume that Swiss science teachers do not put a lot of emphasis on teaching technology in the secondary classroom because this content has not been covered in the earlier curricula (Güdel, 2014, p. 32). Studies of science teachers' knowledge of technological pedagogy in German speaking countries do not exist, but research projects, including one by Goreth et al. (2015), aim to close this gap. Research has shown that the early years of secondary education are crucial in terms of the impact a teacher can have on students' views of science and careers involving science (Regan and DeWitt, 2015). Therefore, it is important that Swiss secondary school teachers receive professional training on how to conduct technology lessons in the science classroom that are motivational for students. This was also the aim of the Swiss National Research Project "Explicit reflective technology teaching: Technical competencies, interest in technology and vocational choices" (Heitzmann et al., 2013).

\section{Attitudes Toward Science-Based Technology}

Students' attitudes toward science and technology are a component of the 2006 (Bybee et al., 2009) and 2015 PISA definitions of scientific literacy. These attitudes consist of interest in science and technology, support for scientific inquiry and responsibility for resources and the environment. Attitudes toward science-based technology are not specifically identified. The term technology appears in the framework but only as an appendage to the term science. Hence, it is assumed that attitudes toward science and technology are closely related, which is reasonable from a theoretical point of view. However, there are also some discrepancies; as noted in the framework, science and technology have complementary roles in society (Organisation for Economic Co-operation and Development [OECD], 2006a). Thus, it can be concluded that the relationship between science and technology is not yet well defined.
The present study used the expectancy-value model of Wigfield and Eccles (2002) to investigate the motivational attitudes of students toward science-based technology. This model has been used with success previously in science research (Riegle-Crumb et al., 2011; Wang and Degol, 2013; Henriksen et al., 2015a). It explains achievement-related choices by the value a student attributes to a task and the student's competence and beliefs related to that task (Figure 1). These beliefs, in turn, determine the student's expectations for success. In other words, a student's "Yes" response to certain questions (e.g., "If I try hard, can I solve the technical problem?" or "If I solve the technical problem, will the result be valuable or rewarding to me?") is indicative of motivation to attempt to perform a technical task.

Eccles et al. (1999) reported that both the expectation of success and the subjective task value ultimately predict career choices. The students' attitudes are also assumed to be influenced by the socializer's behavior and beliefs, and by the cultural milieu. Gender influences life choices through socialrole identity formation, collective identity and the hierarchy of values associated with the individual's expectancies for success. For example, young women place more value than young men on making occupational sacrifices for one's family and on having a job that allows one to both help others and do something worthwhile for society (Eccles, 2009). On the task value side, the model includes utility value, interest and enjoyment, attainment value (important for identity), and the costs of engagement. The last two of these are especially important for understanding the impact of gender roles on the value students attach to subjectrelated activities in school. In this study, the enjoyment of science seemed to be primarily framed in terms of the handson element of experiments. A longitudinal study of elementary school students by Archer et al. (2010), determined that younger students enjoy school science when it is framed in terms of "doing science" rather than being or becoming scientists. In their interviews, many of the students reported that they also practiced science at home. Archer et al. (2010) assumed that this result might help to explain different patterns of student engagement with science. The experiments that were conducted were more or less formal or related to the school's science lessons, depending on the social class of the students.

\section{Career Interest in Jobs Related to STEM}

Early adolescence is a time of active vocational development when young people contemplate school and careers, obtain parttime jobs, make decisions about additional subjects to take and narrow the field of possible career choices. Key attitudes related to career choices include personal interests, self-efficacy expectations, and outcome expectations (Lent et al., 1994), which must be linked to specific subject domains, e.g., technology and engineering, to have meaning (Betz and Hackett, 2006). As most research is conducted within the STEM framework, we refer to the broader concept of STEM and not to the more specific fields of technology and engineering in the following sections.

Career intentions for STEM have been reported to correlate with general interest in STEM subjects (Kudenko and GrasVelázquez, 2016). A STEM background (e.g., having a parent who works in a STEM field), can have a positive influence on 


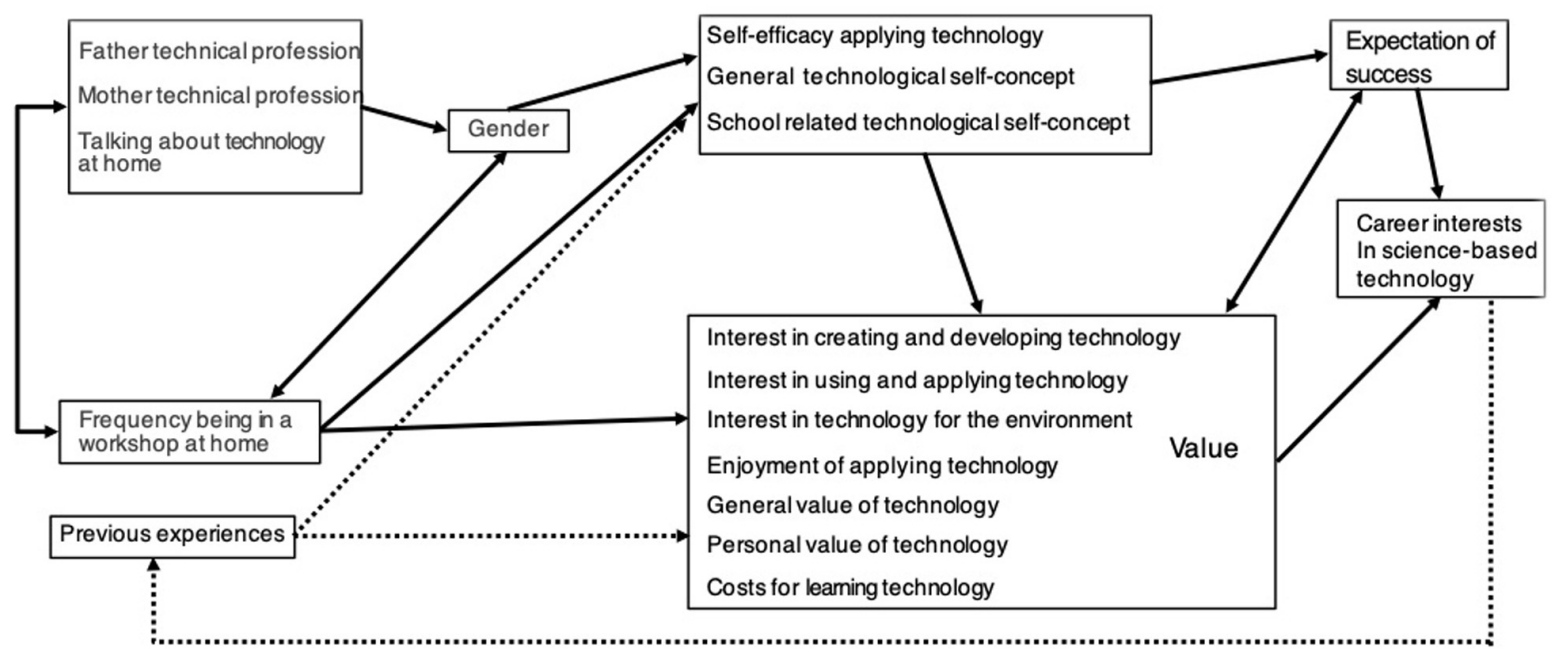

FIGURE 1 | Research model based on the expectancy-value model of Eccles and Wigfield (2002). Dotted lines indicate the associations that were not analyzed in this research.

the student's self-concept and career choice (Wang and Degol, 2013; Moakler and Kim, 2014; Regan and DeWitt, 2015). Parental professions can improve motivation through role modeling, encouragement, and exposure to or familiarity with a field (Chakraverty and Tai, 2013). In general, parents' knowledge of STEM occupations seems, however, to be limited, resulting in negative outcomes for careers in the STEM field (Hall et al., 2011). A specific concern in the research of Hall et al. (2011), which involved a rural area in the United States, was the limited knowledge of science and math teachers as well as job counselors with respect to STEM careers, especially engineering. Students' attitudes toward science were found to correlate with their outcomes in science, and consequently, predict STEM study selection (Guo et al., 2015). These findings suggest that interventions targeting the promotion of academic performance and STEM pathways should seek to enhance both self-concept and intrinsic value, e.g., enjoyment. It should be noted that girls do not generally have lower academic scores in STEM subject areas (Stoet and Geary, 2018). Capobianco et al. (2015) reported higher scores for girls performing engineering activities in almost all five grades in elementary school. Unfortunately, from the point of view of female STEM-promotion, girls who perform well in STEM subjects seems to do even better in language subjects (Stoet and Geary, 2018). Based on expectancy-value theory, individuals pursue careers in subjects in which they are most competent. Hence, girls choose a profession in the humanities or social sciences.

Teaching projects that aim to enhance students' interest and enjoyment of science and technology activities appear to have the potential to spark later interest in a career in these fields (Mohd Shahali et al., 2017). Capobianco et al. (2015) examined whether elementary school students' engagement in engineering designbased science learning activities had an effect on their engineering identity development. The results suggest that when exposed to standards-based engineering learning activities, elementary school students demonstrate improved understanding of the work of an engineer and their own abilities to engage in science and math problem solving, and stronger aspirations of becoming engineers. Hence, their self-concept for science develops positively. Another possible method of altering students' self-concept is utility value interventions, such as identifying the personal utility-value connections between students' lives outside of the classroom and what they are learning in class. These practices have been found to be effective for triggering interest and promoting academic performance in STEM topics (Hulleman and Harackiewicz, 2009; Aeschlimann et al., 2016). Out-of-school experiences also seem to enhance students' interest in STEM fields (Henriksen et al., 2015b). In a longitudinal study by Simpkins et al. (2006) participation in out-of-school activities of 5th grade students enhanced their value and selfconcept of their abilities during the following 6th and 10th grades. Dabney et al. (2012) distinguish between structured and unstructured out-of-school experiences. Structured experiences include museum visits and programs (e.g., science groups, clubs or camps, and science and mathematics competitions). However, a large number of unstructured activities occur without any sort of scaffolding other than the individual pursuit of activities, such as conversations or socializing, tinkering with objects, engaging in personal (science) hobbies, and reading non-fiction science and science fiction. Out-of-school experiences might stimulate students' interest/enjoyment more than their utility values; engaging students in authentic science, e.g., a lab visit, can be more relevant than presenting future job opportunities (Masson et al., 2016). Similarly, among students who experienced working in a lab at a university, Glowinski and Bayrhuber (2011) found that upper secondary students' interest in science experiments was divided in terms of their interest in working with laboratory equipment, research conducted in such labs and the out-of-school experience itself. In particular, among those students with a lower previous interest in science who did not use 
various sources of information about science outside of school, the novelty effect of the student lab experience seemed to have remained in the forefront when explaining their interest in the lab visit. Nevertheless, students' participation in out-of-school activities, their gender and middle-school interest in science and mathematics play a significant role in university career interest in STEM (Dabney et al., 2012).

Less well known are programs that aim to provide students with hands-on experience in science experiments in various industries. Levine and DiScenza (2018) designed, implemented, and evaluated a full-day outreach program for high school girls that focused entirely on activities related to the sugarindustry. The authors reported the development of career interest during the project's time. Such factory visits are also helpful for increasing students' knowledge of the professions. Australian secondary school students, for example, seem to have little idea of the range of workplace possibilities that a science degree offers (Rodrigues et al., 2007). They did not realize that careers in science, engineering, and technology open up opportunities in areas, such as communication, information management, and planning and organizing. These skills are rated highly by the students, but they do not associate them with science jobs. Similarly, in a study conducted in Switzerland by Aeschlimann et al. (2016), more extensive information about STEM professions predicted STEM study choice.

\section{Research Questions}

As the basis of our research, we followed the expectancy-value model of Wigfield and Eccles (2002), as presented in the section on attitudes, and we specified the variables for science-based technology (Figure 1). It is assumed that two main forces, i.e., the expectancy of success and the value of science-based technology, predict a student's career interest in the technology and engineering professions. Further influences, such as gender, technical profession of the father/mother, how often technical subjects are a conversational topic at home, and how often the student spends time in a workshop at home (Becker and Maunsaiyat, 2002) were included as context variables.

Our main question is as follows: What predicts students' career interest in technology-and engineering-related jobs?

Our sub-questions are:

1. What are the attitudes of secondary school students toward science-based technology?

2. Does the measurement model depict the theoretical research model?

3. Which factors contribute to the prediction of students' interest in a career in the technology and engineering fields?

\section{METHODS}

\section{Design}

Our research design was embedded within a bi-national STEM implementation project. An equal status concurrent mixedmethods (QUAN + QUAL) design (Schoonenboom and Johnson,
2017) was used to analyze the combined student and teacher data at the school and project levels. The two strands were analyzed independently, and then were integrated and analyzed together (Figure 2). One aim of the mixed-methods design was to triangulate the results of each strand.

The Swiss-Austrian project began in 2016 and ended in 2018, lasting 2 years. Its main goal was to connect industry with schools to motivate secondary school students to value STEM-related subjects. At the beginning of the project, the initiative to form an industry-school partnership was proposed by two universities who tracked the first contact. As the project became more visible, schools and industries took the initiative as well. As part of the project, secondary school students with a technology and engineering background from the regions of St. Gallen $(\mathrm{CH})$ and Vorarlberg (AT) visited a local company and worked on STEM-tasks related to the company's products. Each local school-industry partnership in the project was designed by teachers and industry employees, based on their requirements. Hence, the duration, content, and tasks differed for each schoolindustry partnership. The teacher(s) organized the factory visits and discussed the experience with the students' afterward.

In the original project, an evaluation but not scientific research was planned. At a later stage, however, the universities from the two countries decided to seize the opportunity to implement a research strand as well. Therefore, only the participants in the projects in 2017 and later were included in the research. Data collection was a rolling process, depending on the start of each school-industry partnership, and it occurred between January 2017 and April 2018.

\section{Participants}

The convenience sample consisted of students $(N=337)$ from 17 lower-level secondary school classes in seven schools in the eastern part of Switzerland. The mean age was 13.5 years, 141 were male, 196 were female, and the majority of students were enrolled in grade 7 . Written informed consent was obtained from the parents. All of the classes participated in the project titled, "STEM becomes a habit in schools." We also interviewed all teachers ( $N=12$; four females) who were responsible for teaching science lessons in those schools respectively classes.

\section{Instruments}

The student questionnaire consisted of items on students' attitudes toward science-based technology and variables related to the students' background, e.g., gender, father/mother's job, and the importance of technology at home. Our items refer to the expectancy value model of achievement designed by Eccles and Wigfield (2002) (see Figure 1). Most of the items were adapted from the published research literature and are presented in the Supplementary Table 1. Items related to costs were adapted from Flake et al. (2015) and Kosovich et al. (2014). Items related to interest and values were adapted from Güdel (2014) and the 2006 PISA (Organisation for Economic Co-operation and Development [OECD], 2006a). Four items asked about the students' future job aspirations, as in the study by Riegle-Crumb et al. (2011). In the German language, the term technology relates solely to science-based technology but not to the use of computers 
Procedures:

337 students in 7 classes

Questionnaire on science-based technology attitudes

Product:

Structural equation model (SEM) for career intentions



FIGURE 2 | Flow diagram of the mixed-methods research design.

(known as informatics). Therefore, we used the term technology without further clarification in our questionnaire. Three of the scales covered the expectancy dimension of the model (sample item in brackets): (1) general technological self-concept (Although I make efforts, I have problems applying technology), (2) selfefficacy in applying technology (I feel capable of changing a light bulb), and (3) school-related technological self-concept (I follow technology easily as well as related topics at school). Seven other scales formed the value component of the model: (1) interest in applying technology (I'm interested in repairing technical tools), (2) interest in creating technology (I'm interested in developing a technical tool in a team), (3) interest in technology related to the environment (I'm interested in developing advertisements for environmental compatible tools), (4) enjoyment of applying technology (I like to take technical tools apart), (5) general value of technology (Technology is important for society), (6) personal value of technology (Technology is very relevant to me), and finally, (7) costs of learning technology (It is too much effort for me to learn to understand how a technical tool functions). We utilized a 6-point Likert scale to score the questionnaire's items ( 6 = absolutely agree, $5=$ agree, $4=$ somewhat agree, $3=$ somewhat disagree, 2 = disagree, and 1 = absolutely disagree). Ratings of all items in the scales were summarized and checked for reliability (Cronbach's alpha are shown in the Supplementary Table 1). In line with Eccles and Wigfield's model, we included five context variables related to the students' cultural milieus and family backgrounds. These items enquire about gender, whether the student's father or mother is in a technical profession, how often technical subjects are discussed as a topic at home, and how often the student spends time in a workshop at home.

The interview followed a semi-structured guideline, which ensured that all teachers were asked the same key questions. After they answered questions related to the subjects of mathematics and science, the teachers were instructed to discuss the role of technology in their lessons, the topics they presented, and the methods they used accomplish their goals. A section on the student's career choice followed, e.g., students' current career intentions and explanations for their choice. Finally, the teachers were asked about their expectations and concerns related to the school-industry project.

\section{Analyses}

Statistical analyses (descriptive analysis and correlations) of the student data were conducted with SPSS software. Exploratory factor analysis and structural equation models (SEMs) were calculated using MPlus 8 to analyze the relationships of the expectancy-value model. Model fit indices of the items were reviewed to determine whether the model was appropriate (Hu and Bentler, 1999).

We used qualitative content analysis as the methodological framework for the analysis of the interview data (Mayring, 2000). The coding process followed the structure of the guideline; accordingly, some codes were developed deductively and others were developed inductively, as part of the coding process. Qualitative content analysis does not yield counts or statistical significance; instead, it uncovers patterns, themes, and categories important to a social reality (Schilling, 2006). Quantification of qualitative data generated from a small number of interviews does not make sense (Patton, 2015, p. 657). We conducted computer-assisted content analysis on the interview data using MAXQDA 2018 software. All coding was done by the first author. To enhance the credibility of our study, the results of the coding analysis and alternative interpretations of the material were thoroughly discussed among members of the research team (Patton, 2015). The data sources were integrated after the separate analysis of each source. The aim was to bring together the 
students' and teachers' voices and to compare and complement the findings from each analysis (Bazeley, 2012). The ultimate goal of our data triangulation was to validate the empirical constructs used in this research.

\section{RESULTS}

\section{Quantitative Analysis}

The attitudes of the secondary school students related to selfconcept and value of technology were not very high compared to the findings of Britner and Pajares (2006), but were similar to those of Brown et al. (2016). The students' ratings were mostly 4 (somewhat agree), with large standard deviations for items pertaining to interest (Table 1). Ratings on all scales from the expectancy-value model related to the students' self-beliefs were correlated (Table 1). The same was true for ratings on the scales pertaining to students' value of technology. Ratings on the competence and value scales were correlated, except for students' general value of technology. Students valued technology on a general level, but at the same time, they did not feel competent in technology. However, the more competent they felt, the more they valued technology for themselves. Ratings on the cost scale were negatively associated with all of the other scales, indicating the more competent a student felt and the higher the student valued technology, the lower the cost the student needed to invest to achieve success in a technology-related task.

Ratings on both expectancy and value scales were correlated with career choices. Students' interest in a future job in a technological field was not high, but the standard deviation was large $(M=3.49$ and $S D=1.38)$. The ratings of approximately one quarter of the students showed high means $(\geq 5)$, indicating interest in a future science-based technology career.

To test our hypothetical model (Figure 1), we created a SEM consistent with this research model. The SEM contained 10 manifest variables for the two latent variables - expectancy and value and the paths between expectancy, value, and career interests for technology and engineering professions. The five context variables were not included in this first model. Its expected structure, which is illustrated in Figure 1, however, showed unsatisfactory fit indices: CFI $=0.83$, TLI $=0.78$, and RMSEA $=0.17$. Therefore, we conducted exploratory factor analyses (EFA; oblique rotation of geomin) to determine which of the observed variables might form a manifest construct and to construct an alternative better fitting SEM. Based on the results of the EFA and theoretical considerations (see section "Discussion and Conclusion"), we regrouped our manifest variables and dropped two of them: general value of technology and interest in creating and developing technology. One of the new latent factors contained four scales referring to value, costs, and self-concept. The other factor included four scales focused on the application of technology. Therefore, we labeled them "self-concept for science-based technology" and "motivation for applying sciencebased technology." Thus, instead of distinguishing expectancy and value, our model emphasized: (1) attitudes that were more closely related to the student's self-concept and (2) attitudes that covered task-related aspects. The second factor was similar to the intrinsic values in the model of Eccles and Wigfield (2002).

We reconstructed a SEM with these two new latent factors and eight manifest variables (CFI $=0.99$, TLI $=0.98$, and RMSEA = 0.06). The final model (Figure 3) included the five context variables, e.g., father or mother having a technical profession and the variable of career interest. The context variables were expected to show indirect effects on career choice (Lent et al., 2005). This final model was created to predict students' career interests in the technology and engineering sectors before the project started, and it showed good fit indices: $\mathrm{CFI}=0.96$, TLI $=0.95$, and RMSEA $=0.07$.

In this model (Figure 3), the choice of a technology or engineering career was strongly predicted by the latent factor selfconcept $(\beta=0.87)$, and self-concept for science-based technology was a predictor of students' motivation to apply science-based technology $(\beta=0.77)$. Students' eagerness to apply technology, however, was not related to future career choice. Girls enjoyed applying technology, but their self-concept (including values and costs) concerning it was significantly lower $(\beta=-0.57)$ than it was for boys. When a father's profession was in the technology field, the student's self-concept was significantly higher. However, no significant effects were found for mothers who were technical professionals. It must be pointed out that only 20 girls had mothers in technical professions that could serve as role models. Discussing technology at home raised students' self-concept and values while lowering their costs of technology. Finally, students' frequency of spending time at home in a workshop predicted their motivation for applying technology as well as their self-concept.

\section{Qualitative Analysis}

The aim of qualitative content analysis is to pay attention to unique themes that illustrate the range of the meanings of a phenomenon. In this study, the deductive part of deriving codes was based on the interview's structure, and codes were added inductively during the coding process. Finally, the relevant themes emerged from the participants' responses to the study's questions: (1) teaching of technology, curriculum, lessons, (2) role and relevance of technology education, (3) students' attitudes toward science-based technology, and (4) students' career choices, with respect to the technology and engineering professions. We begin this discussion with the last theme and proceed to the first theme. In this way, we move from the students to the teachers and their teaching.

The analysis of the coded statements indicated that the professions in the technology and engineering fields were very far away from students' thoughts. This was the case, especially for girls. The teachers also mentioned a general lack of any real concept of what jobs existed in these fields. However, it should be noted that most of the students in our sample were still in grade 7 at the time of the survey, and career counseling in the school had not started. The teachers reported that the students' career choices were influenced by a number of people. Among them were older students in the school, parents, relatives, and job counselors. Due to the influence of their parents, students aimed for white collar jobs. Many students aspired to an 
TABLE 1 | Descriptive statistics and correlations of students' attitudes toward science-based technology.

\begin{tabular}{|c|c|c|c|c|c|c|c|c|c|c|c|}
\hline & $M$ & $S D$ & 1 & 2 & 3 & 4 & 5 & 6 & 7 & 8 & 9 \\
\hline 1. Self-efficacy in applying technology & 4.12 & 1.07 & - & & & & & & & & \\
\hline 2. General technological self-concept & 3.88 & 0.95 & 0.47 & - & & & & & & & \\
\hline 3. School related technological self-concept & 3.91 & 0.91 & 0.56 & 0.58 & - & & & & & & \\
\hline 4. Interest in creating and developing technology & 3.71 & 1.31 & 0.51 & 0.40 & 0.57 & - & & & & & \\
\hline 5. Interest in using and applying technology & 3.50 & 1.34 & 0.75 & 0.49 & 0.60 & 0.71 & - & & & & \\
\hline 6. Interest in technology for the environment & 3.58 & 1.12 & 0.41 & 0.29 & 0.43 & 0.73 & 0.52 & - & & & \\
\hline 7. Enjoyment of applying technology & 3.63 & 1.30 & 0.77 & 0.50 & 0.63 & 0.64 & 0.90 & 0.45 & - & & \\
\hline 8. General value of technology & 3.89 & 0.89 & 0.32 & 0.31 & 0.43 & 0.47 & 0.44 & 0.38 & 0.40 & - & \\
\hline 9. Personal value of technology & 3.92 & 1.06 & 0.51 & 0.48 & 0.69 & 0.61 & 0.67 & 0.42 & 0.65 & 0.55 & - \\
\hline 10. Costs of learning technology & 2.96 & 0.96 & -0.55 & -0.57 & -0.61 & -0.56 & -0.66 & -0.38 & -0.65 & -0.33 & -0.57 \\
\hline
\end{tabular}

$N=334$; correlation for all scales: $p<0.001$.

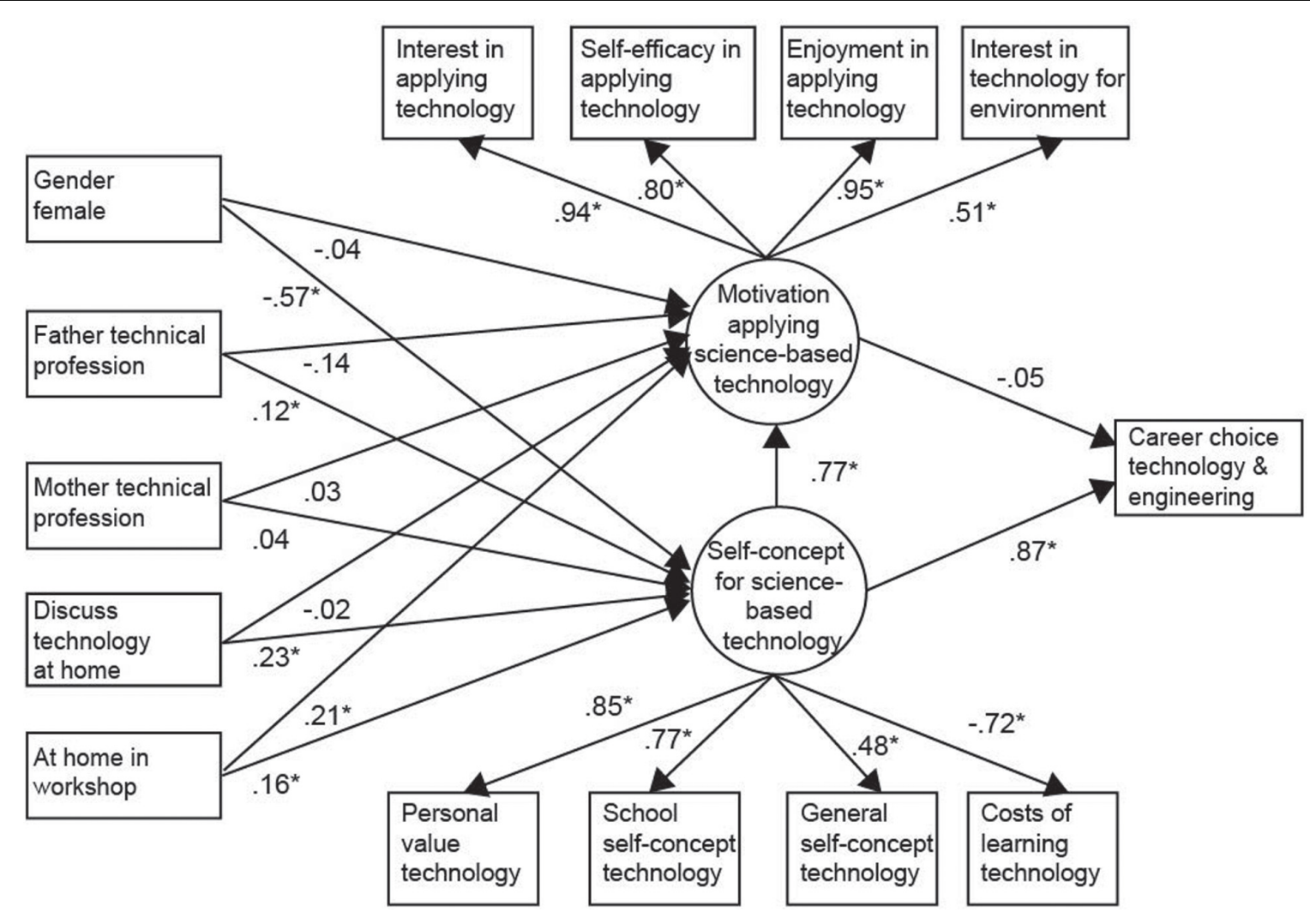

FIGURE 3 | Structural equation model of secondary students' career preferences for technology and engineering professions. Note: $N=321$; *all paths $p<0.05$, estimates are standardized.

academic career because it has higher social value than a craftbased apprenticeship. Students had prejudices against jobs in technology and engineering companies, as stated in the following response during the interview:

(I notice that) technical professions on construction sites, my first career, are no longer popular, that it can be dirty to work there, it can also get cold there, such professions could also bring a lot for life (teacher R, male).

According to the teachers, lack of competencies in mathematics prevented students from developing an interest in STEM subjects. However, some teachers stated that girls nowadays show as much interest as boys in science lessons. The students lack confidence to study science topics, in general, and to apply science in particular. They already have trouble arranging an electric circuit, which is part of the curriculum. Boys seem to have an advantage because they utilize more technical tools in their spare time; they are more often seen repairing items, e.g., bicycles.

There are also many prejudices among these girls, which you can feel during the lessons. If they really went to get a taste (apprenticeship) and had to work for a week filing, drilling, and 
milling, I think they would have fun. But of course they don't take a drill into their hands at all. They say, "because I can't do it, so I don't do it" and "I also don't take a saw in my hand, because I can't do that, so I don't do it." So here it is, they have no experience at all with it (teacher $\mathrm{C}$, male).

Shifting from expectancy to value attitudes, the teachers stated that the students have trouble seeing the connections between science-based technology topics in school and in real life. This results in the lower values in science-based technology subjects. According to the teachers, to find appropriate technology topics for girls. Hence, female students do not feel included in the technology lessons. The teachers reported that the students show enjoyment when they can do hands-on experiments. It is important to them that the students are allowed to tinker during technology lessons.

It's important for me to try it out together with the students. For example, if you have a problem here and now, you can just build something that works. Technology is something practical; you can imagine something and try it out (teacher S, female).

For the teachers, it seems to be crucial that their students are able to use a screwdriver and that they no longer fear situations requiring repairs. Furthermore, they feel the lessons should prepare students to make decisions in their future lives, e.g., how they will treat the environment, as one teacher mentioned:

Students should have, at the minimum, an understanding of what we are actually talking about when we talk about atomic energy or when we talk about an energy exit. What does it mean when we talk about saving energy? What does global warming mean? It is important that they have the minimum amount of basic knowledge and that they understand what this world is all about (teacher $\mathrm{C}$, male).

When the teachers had to specify what they typically do when they teach technology in their science lessons, they often referred to content areas that were part of chemistry or physics lessons. They mentioned topics, such as experimenting with electric circuits, assembling an electric motor, or applying chemical separation methods, which are all traditional content areas in the science curriculum. Rather, teachers stated that it was in the optional subjects that a more tinkering type of technology was more likely to appear, e.g., as part of a project's work. The reasons given by the teachers for this limited realization of technology education in ordinary science lessons were that the technology lessons required too much time and material.

\section{Integrating the Study's Quantitative and Qualitative Results}

We used the qualitative data to validate our quantitative results (Creswell and Plano Clark, 2011, pp. 210-212). To be more precise, we intended to check whether the two latent factors of the SEM could be trusted with respect to their construction. This was accomplished by arranging the themes (coding) derived from the qualitative data in a matrix according to the theoretical and empirical quantitative model. Table 2 shows that the themes - the teachers' responses to the interviews - could be ordered in a meaningful way into two columns representing the theoretical factors and two rows depicting the empirical factors. We conclude from the triangulation of our data that the interpretation of our results in the next section is plausible.

\section{DISCUSSION AND CONCLUSION}

With respect to our first question about the state of secondary school students' attitudes toward science-based technology and career aspirations, we obtained rather negative attitudes toward both, as expected. These results are almost identical to those from other Western European countries (Kudenko and GrasVelázquez, 2016). At least in our sample, approximately a quarter of the students were highly interested in a technology career. As in other studies (Wang and Degol, 2013), girls tended to have less favorable attitudes than boys toward STEM subjects and they exhibited lower job aspirations in the STEM field. With respect to the contextual factors in the value-expectancy model, we found that different socio-cultural aspects might have played a role. However, these factors - such as whether a father has a job in a technology-related company - have an effect mainly on the student's self-concept and not on the motivation for applying technology.

The second question was whether the empirical model would work as postulated in the theoretical model. This was partly confirmed. Our SEM consisted of manifest variables derived from the theoretical research model. However, we had to rearrange these manifest variables in two latent variables that differed from the original expectancy-value model of Eccles and Wigfield (2002). While one factor consisted of variables related to values and self-concept, the other factor represented the interest value or the application of science-based technology. Eccles (2009) views the interest value as being based on the anticipated enjoyment of engaging in the activity itself and thinks it relates directly to the activity itself and the pleasure it provides the individual while engaged in it. We had to separate the interest value from the other expectancy and value attitudes. This shift in focus made sense from a theoretical point of view. Given the definition of science-based technology, it is clear that technology is viewed as applied science; thus, application is, by definition, a salient feature of the research topic. One implication of a study by Ainley and Ainley (2011) is that measurement strategies and research designs targeting students' immediate experience and the more common general levels of measurement, such as personal values, should be used to assess achievement emotions because they provide a complementary perspective to learning science. Our measurement model followed these two perspectives for learning technology.

The third research question considered the factors that contribute to the prediction of the students' career interest for science-based technology. Technology education has a strong connection to the application of knowledge and skills in fields like transportation or communication. Typical values relate to sustainability, risk/failure, and social interaction (Rossouw et al., 2011). Our empirical model suggests that up to now, career interest in science-based technology jobs seem to be 
mainly influenced by students' self-concept based on traditional school science, and not by the application of science knowledge to practical problems. In the teacher's interviews, they also postulated that students do not experience many opportunities to apply science-based technology.

Archer et al. (2010) described a key dilemma for science education, namely that students can report enjoying science (e.g., they may find it fun, exciting, important, and interesting) but might still see it as "not for me" and choose not to study it at a higher educational level. From our model, we can conclude that this is probably due to the student's self-concept, including their personal values that remain unaffected by enjoyment. In their analysis of the relationships among value of science, enjoyment, and interest, Ainley and Ainley (2011) showed that enjoyment and interest were closely associated. It appeared that when students believed that the topics they were dealing with in science had personal relevance and meaning for their lives (high value), they were more likely to experience enjoyment and interest from their involvement with science content. The model in Figure 2 shows that the students' expectancy attitudes predicted their motivation to apply science. Hence, if the secondary students from this sample see connections between what they learn in science at school and their (future) lives it is more likely that they will be motivated to pursue science-based technology. This conclusion emerged from the analysis of the teachers' interviews. A recent study by Buckley et al. (2018) with Irish post-primary students (approximately 18 years old) supports the assumption that students' selfconcept for science-based technology is primarily established by traditional science lessons, with a greater foundation in learning concepts and understanding ideas. They found that science students, compared to engineering students, possessed different knowledge types. Students that did not take optional technology courses mainly acquired declarative knowledge, while those students that did take them needed to develop declarative and procedural knowledge. Hence, possessing a high level of procedural knowledge should be related to having a high self-concept for technology. In their research, the authors conclude there is a need for compulsory technological education for all students, considering that procedural knowledge is in high demand in the students' future work world. A complementary study by Masson et al. (2016) that explored the additional role of self-concept showed that participating in a technology and design activity did not lead immediately to a shift in career goals, but it raised students' self-confidence in the long term.

There are also contextual factors that help to understand career choice. As in other studies, we detected an indirect effect of gender on career choice. One explanation among others that was also mentioned in the teachers' interviews, was that female students might have heard negative experiences from their colleagues, friends, and relatives. Eccles (2011) reported that women in highly competitive male-dominated occupations, such as engineering, often face discrimination and harassment in their jobs, as well as more subtle forms of disapproval. The anticipation of these kinds of negative experiences could deter young women from selecting male-dominated occupations. 
A limitation of this study is that the cross-sectional design does not consider the student's technology identity development. According to Kroger (2006), identity formation is generally examined longitudinally. Hence, we could only explore the relationships between attitudes and career interests, but not effects. However, our results are consistent with the results of the longitudinal model of Simpkins et al. (2006). The main difference is that they constructed two separate models for interest and self-concept. Thus, the relationship between interest and self-concept remained unexplained in their research. Another limitation of the present study is that the participant pool of secondary school students and teachers were from one Swiss area in the northeast, which may limit the generalizability of the results.

Nevertheless, technology is not yet a prominent topic in science lessons at secondary schools in Switzerland, which is also not unusual in other regions (Jones et al., 2013). Research findings suggest that when new curricula are fully implemented more studies will be needed that explore differences in attitudes and knowledge regarding science and technology. Until then, visits to industries as part of our project "STEM becomes a habit in schools" represents a unique opportunity for students to uncover talents or interests they might have in the technology and engineering professions. Up to now, students who have had no contact with technology at home did not have opportunities to develop positive attitudes during adolescence. They have missed not only exposure to procedural knowledge for science subjects, but also basic information about jobs in the technology and engineering sector. Industry visits promote prospective graduates' insight into the work world. Another implication of the results is the importance of remaining attentive to informing students about the career opportunities available in science (Tytler and Osborne, 2012). After all, students cannot aspire to that which they have never seen. Such work needs to be done by teachers and job counselors. Industry-school projects provide a forum where teachers can acquire knowledge about job opportunities. It will

\section{REFERENCES}

Aeschlimann, B., Herzog, W., and Makarova, E. (2016). How to foster students' motivation in mathematics and science classes and promote students' STEM career choice. A study in Swiss high schools. Int. J. Educ. Res. 79, 31-41. doi: 10.1016/j.ijer.2016.06.004

Ainley, M., and Ainley, J. (2011). Student engagement with science in early adolescence: the contribution of enjoyment to students' continuing interest in learning about science. Contemp. Educ. Psychol. 36, 4-12. doi: 10.1016/j. cedpsych.2010.08.001

Archer, L., DeWitt, J., Osborne, J., Dillon, J., Willis, B., and Wong, B. (2010). "Doing" science versus "being" a scientist: examining 10/11-year-old schoolchildren's constructions of science through the lens of identity. Sci. Educ. 94, 617-639. doi: 10.1002/sce.20399

Bazeley, P. (2012). Integrative analysis strategies for mixed data sources. Am. Behav. Sci. 56, 814-828. doi: 10.1177/0002764211426330

Becker, F. S. (2010). Why don't young people want to become engineers? Rational reasons for disappointing decisions. Eur. J. Eng. Educ. 35, 349-366. doi: 10. 1080/03043797.2010.489941

Becker, K. H., and Maunsaiyat, S. (2002). Thai students' attitudes and concepts of technology. J. Technol. Educ. 13, 6-20. be interesting to see whether our school-industry project has an effect on our students' attitudes toward science-based technology and on their career interests. In a different study, we have reported outcomes based on the model investigated in this study (Smit et al., 2019).

Finally, based on results of this study, the specific role of technology in the application of science and technology should be further explored. More studies are needed that examine differences between science and science-based technology, attitudes and knowledge, and how they interact in developing career interests in the technology professions.

\section{DATA AVAILABILITY STATEMENT}

The datasets generated for this study are available on request to the corresponding author.

\section{AUTHOR CONTRIBUTIONS}

NR: project leader and theoretical background of the study. CD: scientific collaborator and data sampling. RS: scientific collaborator and data analysis.

\section{ACKNOWLEDGMENTS}

This project was supported by the Interreg IV, Regio Lake of Constance (Project number ABH005).

\section{SUPPLEMENTARY MATERIAL}

The Supplementary Material for this article can be found online at: https://www.frontiersin.org/articles/10.3389/feduc. 2020.00039/full\#supplementary-material

Betz, N. E., and Hackett, G. (2006). Career self-efficacy theory: back to the future. J. Career Assess. 14, 3-11. doi: 10.1177/1069072705281347

Britner, S. L., and Pajares, F. (2006). Sources of science self-efficacy beliefs of middle school students. J. Res. Sci. Teach. 43, 485-499. doi: 10.1016/j.nedt.2016.11.021

Brown, P. L., Concannon, J. P., Marx, D., Donaldson, C. W., and Black, A. (2016). Anexamination of middle school students' STEM self-efficacy with relation to interest and perceptions of STEM. J. STEM Educ.: Innovat. Res. 17, 27-38.

Bryson, J. R., Mulhall, R. A., Lowe, N., and Stern, J. (2018). "Engineering and the skills crisis in the UK and USA: a comparative analysis of employerengaged education," in Value creation Through Engineering Excellence: Building Global Network Capabilities, eds Y. Zhang and M. Gregory (Cham: : Springer International Publishing.), 327-349. doi: 10.1007/978-3-319-56336-7_13

Buckley, J., Seery, N., Power, J., and Phelan, J. (2018). The importance of supporting technological knowledge in post-primary education: a cohort study. Res. Sci. Technol. Educ. 37, 36-53. doi: 10.1080/02635143.2018.1463981

Bybee, R. W. (2000). Achieving technological literacy: a national imperative. Technol. Teach. 60, 23-28.

Bybee, R. W., McCrae, B., and Laurie, R. (2009). PISA 2006: an assessment of scientific literacy. J. Res. Sci. Teach. 46, 865-883. doi: 10.1002/tea.20333

Capobianco, B. M., Yu, J. H., and French, B. F. (2015). Effects of engineering design-based science on elementary school science students' engineering 
identity development across gender and grade. Res. Sci. Educ. 45, 275-292. doi: 10.1007/s11165-014-9422-1

Chakraverty, D., and Tai, R. H. (2013). Parental occupation inspiring science interest: perspectives from physical scientists. Bull. Sci.Technol. Soc. 33, 44-52. doi: $10.1177 / 0270467613509367$

Creswell, J., and Plano Clark, V. (2011). Designing and Conducting Mixed Methods Research, 2nd Edn. Thousand Oaks, CA: Sage.

Dabney, K. P., Tai, R. H., Almarode, J. T., Miller-Friedmann, J. L., Sonnert, G., Sadler, P. M., et al. (2012). Out-of-school time science activities and their association with career interest in STEM. Int. J Sci. Educ. Part B 2, 63-79. doi: 10.1080/21548455.2011.629455

De Vries, M. (2001). The history of industrial research laboratories as a resource for teaching about science-technology relationships. Res Sci. Educ. 31, 15-28. doi: 10.1023/A:1012610328351

Dutrévis, M., Soussi, A., and Genoud, P. A. (2017). Les Attitudes et Aspirations Scientifiques des Filles et des Garçons à Genève. Genève: Service de la recherche en éducation (SRED).

Eccles, J. S. (2009). Who am I and what am I going to do with my life? Personal and collective identities as motivators of action. Educ. Psychol. 44, 78-89. doi: $10.1080 / 00461520902832368$

Eccles, J. S. (2011). Gendered educational and occupational choices: applying the Eccles et al. model of achievement-related choices. Int. J. Behav. Dev. 35, 195-201. doi: 10.1177/0165025411398185

Eccles, J. S., Barber, B., and Jozefowicz, D. (1999). "Linking gender to educational, occupational, and recreational choices: applying the Eccles et al. model of achievement-related choices," in Sexism and Stereotypes in Modern Society: The Gender Science of Janet Taylor Spence, eds W. B. Swann, J. H. Langlois, and L. A. Gilbert (Washington: American Psychological Association), 153-192. doi: $10.1037 / 10277-007$

Eccles, J. S., and Wigfield, A. (2002). Motivational beliefs, values, and goals. Annu. Rev. Psychol. 53, 109-132. doi: 10.1146/annurev.psych.53.100901.13 5153

Fensham, P. J. (1988). Approaches to the teaching of STS in science education. Int. J. Sci. Educ. 10, 346-356. doi: 10.1080/0950069880100402

Flake, J. K., Barron, K. E., Hulleman, C., McCoach, B. D., and Welsh, M. E. (2015). Measuring cost: the forgotten component of expectancy-value theory. Contemp. Educ. Psychol. 41, 232-244. doi: 10.1016/j.cedpsych.2015.03.002

Glowinski, I., and Bayrhuber, H. (2011). Student labs on a university campus as a type of out-of-school learning environment: assessing the potential to promote students' interest in science. Int. J. Environ. Sci. Educ. 6, 371-392.

Goreth, S., Geißel, B., and Rehm, M. (2015). Erfassung fachdidaktischer Lehrkompetenz im technikbezogenen unterricht der sekundarstufe 1 . Instrumentenkonstruktion und erste befunde. J. Tech. Educ. 3, 13-38.

Güdel, K. (2014). Technikaffinität von Mädchen und Jungen der Sekundarstufe I. Geneva: University of Geneva. Thesis.

Guo, J., Parker, P. D., Marsh, H. W., and Morin, A. J. S. (2015). Achievement, motivation, and educational choices: a longitudinal study of expectancy and value using a multiplicative perspective. De. Psychol. 51, 1163-1176. doi: 10. 1037/a0039440

Hall, C., Dickerson, J., Batts, D., Kauffmann, P., and Bosse, M. (2011). Are we missing opportunities to encourage interest in STEM fields? J. Technol. Educ. $23,32-46$.

Heitzmann, A., Safi, N., and Güdel, K. (2013). "Explicit, Reflective Technology Education (EXRETU)-An Intervention Study at Lower Secondary School," in Paper presented at the E-Book Proceedings of the ESERA 2013 Conference: Science Education Research For Evidence-based Teaching and Coherence in Learning. Part 5, Nicosia.

Henriksen, E. K., Dillon, J., and Ryder, J. (2015a). Understanding Student Participation and Choice in Science and Technology Education. Dordrecht: Springer.

Henriksen, E. K., Jensen, F., and Sjaastad, J. (2015b). The role of out-ofschool experiences and targeted recruitment efforts in norwegian science and technology students' educational choice. Int. J. Sci. Educ. Part B 5, 203-222. doi: 10.1080/21548455.2014.900585

Hu, L.-T., and Bentler, P. M. (1999). Cutoff criteria for fit indexes in covariance structure analysis: conventional criteria versus new alternatives. Struct. Equ. Model A Multidiscip. J. 6, 1-55. doi: 10.1080/1070551990954 0118
Hulleman, C. S., and Harackiewicz, J. M. (2009). Promoting interest and performance in high school science classes. Science 326, 1410-1412. doi: 10. $1126 /$ science. 1177067

Jones, A. (2012). "Technology in science education: context, contestation, and connection," in Second International Handbook of Science Education, eds B. J. Fraser, K. Tobin, and C. J. McRobbie (Dordrecht, NL: Springer), 811-821. doi: 10.1007/978-1-4020-9041-7_54

Jones, A., Buntting, C., and de Vries, M. J. (2013). The developing field of technology education: a review to look forward. Int. J. Technol. Design Educ. 23, 191-212. doi: 10.1007/s10798-011-9174-4

Kosovich, J. J., Hulleman, C. S., Barron, K. E., and Getty, S. (2014). A practical measure of student motivation establishing validity evidence for the expectancy-value-cost scale in middle school. J. Early Adolesc. 35, 790-816. doi: $10.1177 / 0272431614556890$

Kroger, J. (2006). Identity Development: Adolescence Through Adulthood. Thousand Oaks, CA: Sage publications.

Kudenko, I., and Gras-Velázquez, À (2016). "The future of european STEM workforce: What secondary school pupils of europe think about STEM industry and careers," in Insights From Research in Science Teaching and Learning. Contributions From Science Education Research, Vol. 2, eds N. Papadouris, A. Hadjigeorgiou, and C. Constantinou (Cham: Springer), 223-236. doi: 10.1007/ 978-3-319-20074-3 15

Lent, R. W., Brown, S. D., and Hackett, G. (1994). Toward a unifying social cognitive theory of career and academic interest, choice, and performance. J. Vocat. Behav. 45, 79-122. doi: 10.1006/jvbe.1994.1027

Lent, R. W., Brown, S. D., Sheu, H.-B., Schmidt, J., Brenner, B. R., Gloster, C. S., et al. (2005). Social cognitive predictors of academic interests and goals in engineering: utility for women and students at historically black universities. J. Counsel. Psychol. 52, 84-92. doi: 10.1037/0022-0167.52.1.84

Levine, M., and DiScenza, D. J. (2018). Sweet, sweet science: addressing the gender gap in STEM disciplines through a one-day high school program in sugar chemistry. J. Chem. Educ. 95, 1316-1322. doi: 10.1021/acs.jchemed.7b00900

Maltese, A. V., and Tai, R. H. (2010). Eyeballs in the fridge: sources of early interest in science. Int. J. Sci. Educ. 32, 669-685. doi: 10.1080/09500690902792385

Masson, A.-L., Klop, T., and Osseweijer, P. (2016). An analysis of the impact of student-scientist interaction in a technology design activity, using the expectancy-value model of achievement related choice. Int. J. Technol. Design Educ. 26, 81-104. doi: 10.1007/s10798-014-9296-6

Mayring, P. (2000). Qualitative content analysis [qualitative content analysis; content analysis; category; induction; intercoder-reliability]. Forum 1.

Moakler, M. W., and Kim, M. M. (2014). College major choice in STEM: revisiting confidence and demographic factors. Career Dev. Q. 62, 128-142. doi: 10.1002/ j.2161-0045.2014.00075.x

Mohd Shahali, E. H., Halim, L., Rasul, M. S., Osman, K., and Zulkifeli, M. A. (2017). STEM Learning through engineering design: impact on middle secondary students' interest towards STEM. Eurasia J. Math., Sci. Technol. Educ. 13, 1189-1211. doi: 10.12973/eurasia.2017.00667a

Ngss Lead States (2013). Next Generation Science Standards: For States, by States. Washington, DC: The National Academies Press.

Nugent, G., Barker, B., Welch, G., Grandgenett, N., Wu, C., and Nelson, C. (2015). A model of factors contributing to STEM learning and career orientation. Int. J. Sci. Educ. 37, 1067-1088. doi: 10.1080/09500693.2015.1017863

Organisation for Economic Co-operation, and Development [OECD] (2006a). Assessing Scientific, Reading, and Mathematical Literacy. (A)Framework for PISA 2006. Paris: OECD Publishing.

Organisation for Economic Co-operation, and Development [OECD] (2006b). Evolution of student interest in science, and technology. (studies). Paris: Global Science Forum.

Organisation for Economic Co-operation, and Development [OECD] (2016). PISA 2015 Results (Volume I): Excellence. (and)Equity in Education. Paris: OECD Publishing.

Patton, M. Q. (2015). Qualitative Research \& Evaluation Methods. Thousand Oaks, CA: Sage.

Regan, E., and DeWitt, J. (2015). "Attitudes, interest and factors influencing STEM enrolment behaviour: an overview of relevant literature," in Understanding Student Participation and Choice in Science and Technology Education, eds E. K. Henriksen, J. Dillon, and J. Ryder (Dordrecht: Springer Netherlands), 63-88. doi: 10.1007/978-94-007-7793-4_5 
Riegle-Crumb, C., Moore, C., and Ramos-Wada, A. (2011). Who wants to have a career in science or math? Exploring adolescents' future aspirations by gender and race/ethnicity. Sci. Educ. 95, 458-476. doi: 10.1002/sce.20431

Robnett, R. D., and Leaper, C. (2013). Friendship groups, personal motivation, and gender in relation to high school students'. J. Res. Adolesc. 23, 652-664. doi: 10.1111/jora.12013

Rodrigues, S., Tytler, R., Darby, L., Hubber, P., Symington, D., and Edwards, J. (2007). The usefulness of a science degree: the "lost voices" of science trained professionals. Int. J. Sci. Educ. 29, 1411-1433. doi: 10.1080/0950069060107 1909

Rossouw, A., Hacker, M., and de Vries, M. J. (2011). Concepts and contexts in engineering and technology education: an international and interdisciplinary Delphi study. Int. J. Technol. Design Educ. 21, 409-424. doi: 10.1007/s10798010-9129-1

Schilling, J. (2006). On the pragmatics of qualitative assessment. Eur. J. Psychol. Assess. 22, 28-37. doi: 10.1027/1015-5759.22.1.28

Schoonenboom, J., and Johnson, R. B. (2017). How to construct a mixed methods research design. Kölner Z. Soziol. Sozialpsychol. 69, 107-131. doi: 10.1007/ s11577-017-0454-1

Simpkins, S. D., Davis-Kean, P. E., and Eccles, J. S. (2006). Math and science motivation: a longitudinal examination of the links between choices and beliefs. Dev. Psychol. 42, 70-83. doi: 10.1037/0012-1649.42.1.70

Smit, R., Robin, N., De Toffol, C., and Atanasova, S. (2019). Industry-school projects as an aim to foster secondary school students' interest in technology and engineering careers. Int. J. Technol. Design Educ. doi: 10.1007/s10798-01909538-0

Stoet, G., and Geary, D. C. (2018). The gender-equality paradox in science, technology, engineering, and mathematics education. Psychol. Sci. 29, 581-593. doi: $10.1177 / 0956797617741719$
Su, R., and Rounds, J. (2015). All STEM fields are not created equal: people and things interests explain gender disparities across STEM fields. Front. Psychol. 6:189. doi: 10.3389/fpsyg.2015.00189

Tytler, R., and Osborne, J. (2012). "Student attitudes and aspirations towards science," in Second International Handbook of Science Education, eds B. J. Fraser, K. Tobin, and C. J. McRobbie (Dordrecht: Springer Netherlands), 597-625. doi: 10.1007/978-1-4020-9041-7_41

Wang, M.-T., and Degol, J. (2013). Motivational pathways to STEM career choices: using expectancy-value perspective to understand individual and gender differences in STEM fields. Dev. Rev. 33, 304-340. doi: 10.1016/j.dr.2013. 08.001

Wigfield, A., and Eccles, J. S. (2002). Development of Achievement Motivation. San Diego, CA: Academic Press.

Xie, Y., and Achen, A. (2009). Science on the Decline? Educational Outcomes of Three Cohorts of Young Americans. Ann Arbor, MI: University of Michigan.

Yeager, D. S., and Walton, G. M. (2011). Social-psychological interventions in education: they're not magic. Rev. Educ. Res. 81, 267-301. doi: 10.3102/ 0034654311405999

Conflict of Interest: The authors declare that the research was conducted in the absence of any commercial or financial relationships that could be construed as a potential conflict of interest.

Copyright (C) 2020 Smit, Robin and De Toffol. This is an open-access article distributed under the terms of the Creative Commons Attribution License (CC BY). The use, distribution or reproduction in other forums is permitted, provided the original author(s) and the copyright owner(s) are credited and that the original publication in this journal is cited, in accordance with accepted academic practice. No use, distribution or reproduction is permitted which does not comply with these terms. 